\title{
Tumor de estroma gastrointestinal extraintestinal gigante: reporte de un caso y revisión de bibliografía
}

\author{
Giant extraintestinal gastrointestinal stromal tumor: Case report and \\ bibliography review
}

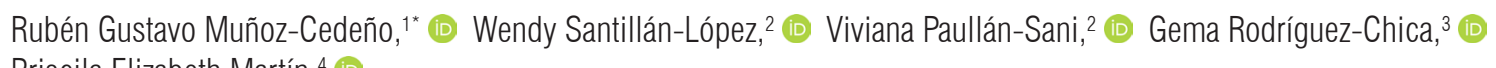

Priscila Elizabeth Martín. ${ }^{4}$ (D)

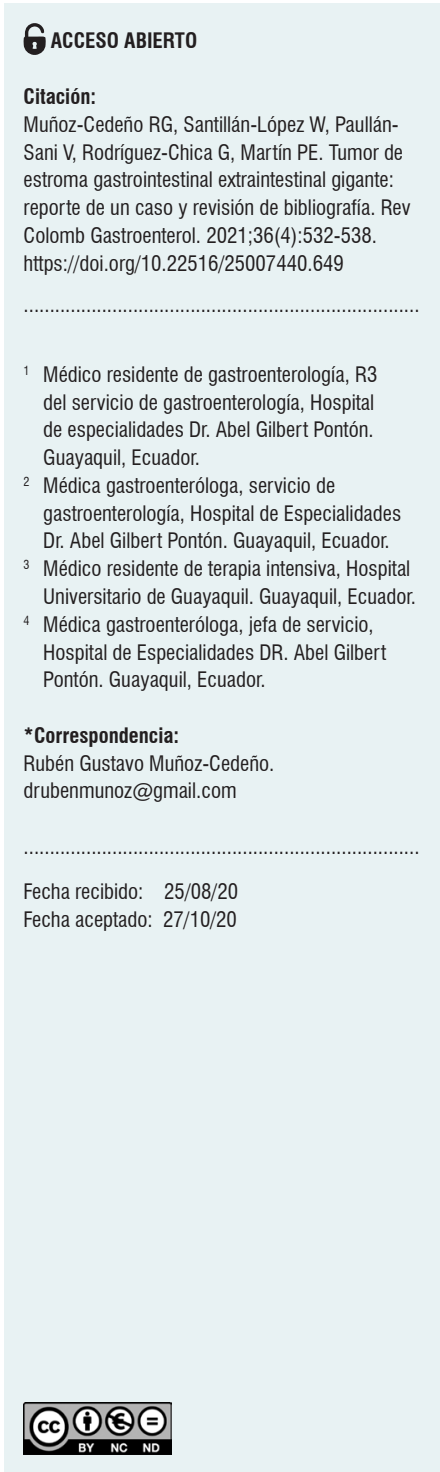

\section{Resumen}

Los tumores del estroma gastrointestinal (GIST) son tumores infrecuentes del tracto digestivo. Sus localizaciones más frecuentes son el estómago, intestino delgado, colon y recto; su aparición en otros lugares fuera del trato gastrointestinal como el mesenterio, epiplón o retroperitoneo es infrecuente. La tomografía axial computarizada (TAC) y la resonancia magnética (RM) son los estudios de imágenes de primera elección. La recesión quirúrgica es el estándar de oro para los tumores localizados y en los tumores avanzados o metastásicos son tratados con imatinib. A continuación, se presenta el caso de un paciente masculino de 53 años de edad sin antecedentes de patologías previos con cuadro clínico de dolor abdominal generalizado, pérdida de peso de $20 \mathrm{~kg}$ aproximadamente, distención abdominal, melena, hematemesis y astenia; en el examen físico presentó abdomen distendido y en la palpación se encontró endurecimiento epigástrico y mesogástrico, y marco colónico izquierdo. En la tomografía de abdomen se observó una masa tumoral de aspecto infiltrativo de aparente origen gástrico, con crecimiento extragástrico e infiltración del bazo, páncreas, raíz mesentérica, epiplón mayor, colon transverso, asas intestinales delgadas e infiltración en el hilio hepático, y metástasis hepática. Además, el cuadro se asoció con enfermedad respiratoria por coronavirus del síndrome respiratorio agudo grave de tipo 2 (SARS-CoV-2; neumonía por coronavirus de 2019 [COVID-19]). Se realizó una biopsia percutánea ecodirigida en el hipocondrio izquierdo y la histología reportó un GIST. En este artículo se revisa la clínica, diagnóstico y tratamiento del GIST gigante extradigestivo.

\section{Palabras clave}

Tumor del estroma gastrointestinal, tumor extradigestivo, tumor gigante.

\section{Abstract}

Giant extraintestinal gastrointestinal stromal tumors (GIST) are rare tumors of the digestive tract. Its most frequent locations are the stomach, small intestine, colon, and rectum. Its appearance in other places outside the gastrointestinal tract such as the mesentery, omentum, or retroperitoneum is infrequent. Computerized axial tomography (CT) and magnetic resonance imaging (MRI) are the imaging studies of the first choice. Surgical recession is the gold standard for localized tumors and advanced or metastatic tumors are treated with imatinib. This study presents the case of a male patient of 53 years with no history of previous pathologies. The patient was admitted with a clinical condition of generalized abdominal pain, weight loss of approximately 20 $\mathrm{kg}$, abdominal distention, melena, hematemesis, and asthenia. Physical examination revealed a distended abdomen and palpation revealed epigastric and mesogastric hardening and left colonic frame. The abdominal tomography revealed a tumor mass with an infiltrative appearance of apparent gastric origin, with extragastric growth and infiltration of the spleen, pancreas, mesenteric root, greater omentum, transverse colon, thin intestinal loops, and infiltration in the hepatic hilum, and liver metastases. Moreover, the condition was related to the severe acute respiratory syndrome type 2 coronavirus (SARS-CoV-2). An ultrasound-guided percutaneous biopsy was performed in the left upper quadrant and histology reported a GIST. In this article medical condition, diagnosis, and treatment of the Giant extraintestinal gastrointestinal stromal, is reviewed.

\section{Keywords}

Gastrointestinal stromal tumor, Extragastrointestinal tumor, Giant tumor. 


\section{INTRODUCCIÓN}

El tumor del estroma gastrointestinal conocido como GIST (gastro-intestinal stromal tumors) es la neoplasia mesenquimática más común del tracto digestivo; sin embargo, su frecuencia representa solo un $0,1 \%$ a $3 \%$ de las neoplasias gastrointestinales, su incidencia es de 10 a 20 casos por cada millón de personas y aproximadamente el $10 \%$ a $30 \%$ son clínicamente malignos. Solo hay reportados de 5000 a 6000 nuevos casos por año en los Estados Unidos ${ }^{(1)}$.Pueden aparecer a cualquier edad, pero predominan en personas de 40 a 70 años $^{(2)}$. Alrededor del $65 \%$ de los GIST se encuentra en el estómago, $25 \%$ a $40 \%$ en el intestino delgado y $5 \%$ a $10 \%$ en el colon o el recto; es muy rara su ubicación en otros lugares digestivos, como el mesenterio, epiplón o retroperitoneo, sitios fuera del tracto gastrointestinal que se reportan en menos de $5 \%{ }^{(3-5)}$. La recesión quirúrgica sigue siendo el estándar de oro para los tumores localizados y los tratamientos farmacológicos están indicados para estadios avanzados de la enfermedad, los que están disponibles en la actualidad han cambiado radicalmente el pronóstico ${ }^{(6)}$.

\section{PRESENTACIÓN DEL CASO}

Se trata de un paciente masculino de 53 años de edad, sin antecedentes patológicos personales, familiares o quirúrgicos, con cuadro clínico de 2 años de evolución caracterizado por dolor abdominal difuso, distensión abdominal y pérdida de peso de $20 \mathrm{~kg}$ aproximadamente, motivo por el cual acudió a médicos particulares (Figura 1). Ingresó desde el área de urgencias por presentar cuadro clínico de 7 días de evolución caracterizado por hemorragia digestiva alta tipo melena 3 veces por día sin inestabilidad hemodinámica, se acompañaba además de dolor abdominal, alza térmica no cuantificada, cefalea, astenia, pérdida del olfato y del gusto desde hacía 5 días. En el examen físico se encontraron la piel y las mucosas pálidas, y en la auscultación hubo estertores crepitantes en ambos campos pulmonares, abdomen distendido con masa visible y palpable en el epigastrio, mesogastrio y marco colónico izquierdo.

Los resultados de los exámenes de laboratorio fueron los siguientes:hemoglobina:2,60mg/dL; hematocrito: $10,30 \%$; leucocitos: $9600 / \mathrm{mm}^{3}$; neutrófilos: $75 \%$; plaquetas:557000; proteína C-reactiva (PCR): 10,6 mg/dL; albúmina: 2,7 $\mathrm{mg} / \mathrm{dL}$; proteínas totales: 5,50; amilasa: $94 \mathrm{U} / \mathrm{L}$; lipasa $552 \mathrm{U} / \mathrm{L}$; dímero D: $2989,7 \mu \mathrm{g} / \mathrm{L}$; procalcitonina: 1,87 $\mathrm{ng} / \mathrm{mL}$; ferritina: $138 \mu \mathrm{g} / \mathrm{dL}$; electrolitos: sodio: 131 $\mathrm{mEq} / \mathrm{L}$, potasio: $3,8 \mathrm{mEq} / \mathrm{L}$, cloro: $95 \mathrm{mEq} / \mathrm{L}$; función renal normal; tiempos de coagulación normales; bilirrubinas normales; prueba serológica para la sífilis (VDRL) no reactiva; antígeno específico prostático (PSA): $0,88 \mathrm{ng} /$ $\mathrm{mL}$; antígeno carcinoembrionario (CEA): $1,06 \mathrm{ng} / \mathrm{mL}$; alfafetoproteína (AFP): $1,57 \mathrm{ng} / \mathrm{mL}$; antígeno carbohidratado 19-9 (CA 19-9): 14,60 U/mL; prueba cutánea de tuberculina o prueba de Mantoux negativa; serología para virus de hepatitis B (VHB), virus de hepatitis C (VHC) y
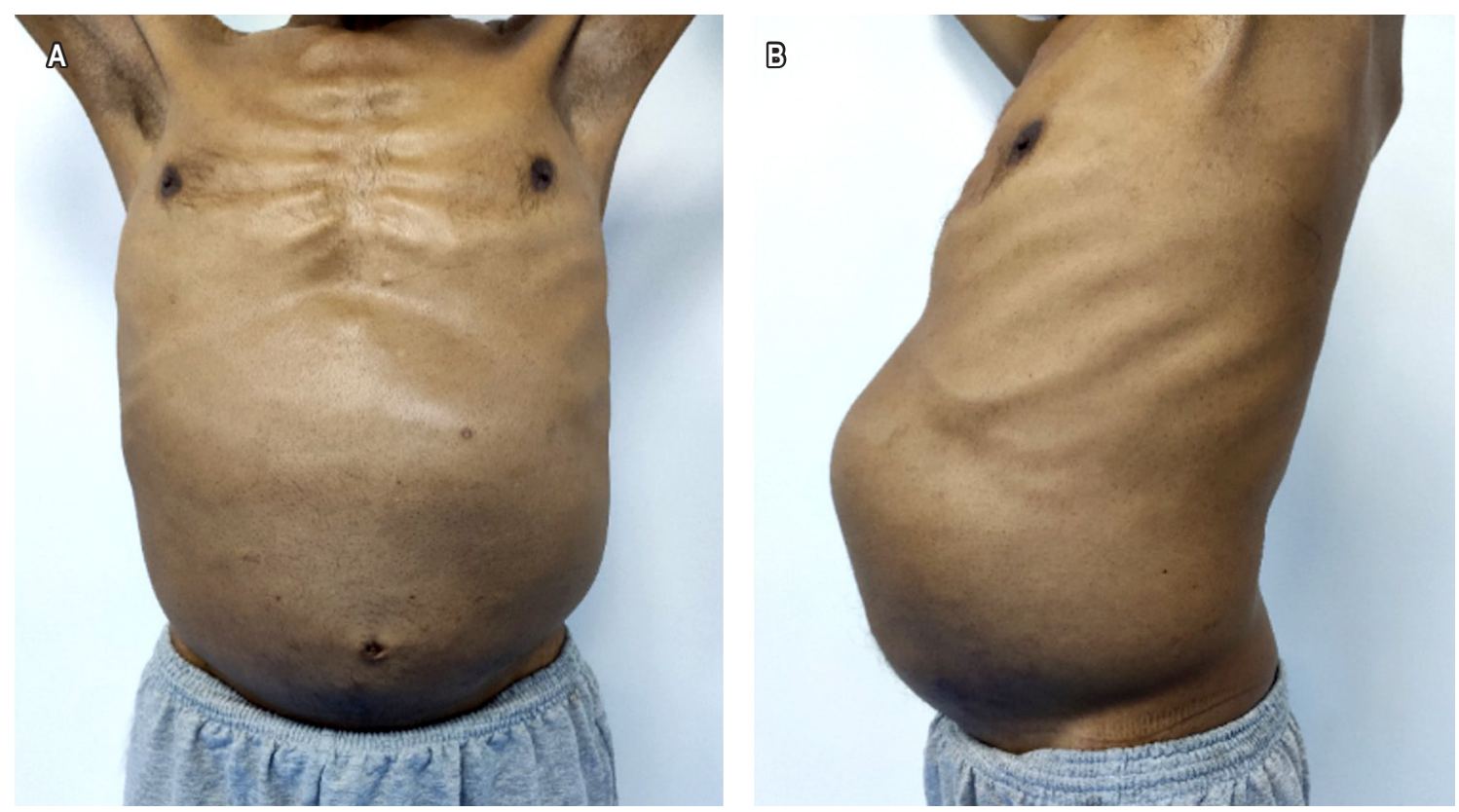

Figura 1. A. Se observa al paciente con distensión abdominal. B. Se observa el abdomen dilatado con presencia de la masa a nivel del epigastrio, mesogastrio e hipocondrio izquierdo. 
virus de inmunodeficiencia humana (VIH) no reactivo; prueba rápida para enfermedad por coronavirus de 2019 (COVID-19), inmunoglobulinas $\mathrm{G}$ ( $\mathrm{IgG}$ ) y M (IgM) positivas. Exámenes imagenológicos incluyeron una ecografía abdominal que reportó una masa sólida hipoecogénica de contornos regulares que nace de la curvatura mayor que mide aproximadamente $23 \times 13 \mathrm{~cm}$ con ecografía Doppler, e incremento de la vascularización.

En la tomografía axial computarizada (TAC) de tórax se evidenciaba consolidación alveolar con infiltración en ambas bases pulmonares en vidrio deslustrado y engrosamiento septal (Figura 2). En la TAC de abdomen y pelvis se evidenció una masa tumoral de aspecto infiltrativo de aparente origen gástrico de aproximadamente de $25 \times 25$ x17 cm con extensa destrucción de la pared y la mucosa, con infiltración endoluminal y crecimiento extragástrico, metástasis hepática (hepatomegalia con dos lesiones hipoatenuantes de aspecto secundario, que miden $72 \times 41 \mathrm{~mm}$ y $86 \times 75 \mathrm{~mm}$ respectivamente en los segmentos hepáticos IV y V, e infiltración del hilio hepático, lo que produce dilatación de la vía biliar intrahepática) infiltración del bazo, del páncreas, de la raíz mesentérica, del omento mayor, del colon transverso, de las asas intestinales delgadas, de la porta y de los ganglios linfáticos periaórticos y pericavales, el mayor mide $13 \mathrm{~mm}$ (Figuras 3 y 4 ).

En cuanto a los estudios endoscópicos, se realizó una videoendoscopia digestiva superior en la que se observó una lesión infiltrativa a nivel de cuerpo gástrico con cicatriz de úlcera gástrica con reporte histopatológico que informó una atrofia gástrica, infiltrado inflamatorio linfoplasmocitario, criptitis proliferativa y congestión vascular. La videocolonos- copia fue incompleta debido a una compresión extrínseca en el colon descendente que impedía el paso del equipo; se observó enfermedad diverticular en el colon sigmoideo sin signos de inflamación o sangrado. Se le realizó una biopsia percutánea ecodirigida en el hipocondrio izquierdo y el informe de histología reportó un tumor del estroma gastrointestinal (GIST), rango mitótico: mitosis $/ 5 \mathrm{~mm}^{2}$, necrosis: no identificada, grado histológico: bajo grado (rango mitótico $\leq 5 / 5 \mathrm{~mm}^{2}$ ), riesgo de evaluación: moderado (10\%), inmunohistoquímica: el antígeno CD117 (C-kit: receptor de tirosina-quinasa) con tinción positiva.

Durante la estadía hospitalaria recibió tratamiento para infección respiratoria por SARS-CoV-2 (neumonía por COVID-19) con lopinavir/ritonavir $500 \mathrm{mg}$ cada 12 horas por 7 días, azitromicina $500 \mathrm{mg}$ cada día por 7 días e ivermectina $6 \mathrm{mg} 3$ tabletas (dosis única), y se obtuvo una mejoría satisfactoria.

Fue manejado por un equipo multidisciplinario conformado por internista, gastroenterólogos, oncólogos, patólogos, cirujanos, imagenólogos y nutricionista, y se determinó que por ser una enfermedad avanzada con metástasis a diferentes órganos y sin planos de resección era candidato para tratamiento farmacológico, por lo que se inició con imatinib y tuvo una buena respuesta. Fue dado de alta sin complicaciones y tiene controles mensuales en consulta externa de oncología hasta la actualidad.

\section{DISCUSIÓN}

Los GIST son tumores no epiteliales poco frecuentes del aparato digestivo. Mazur y Clark introdujeron el término
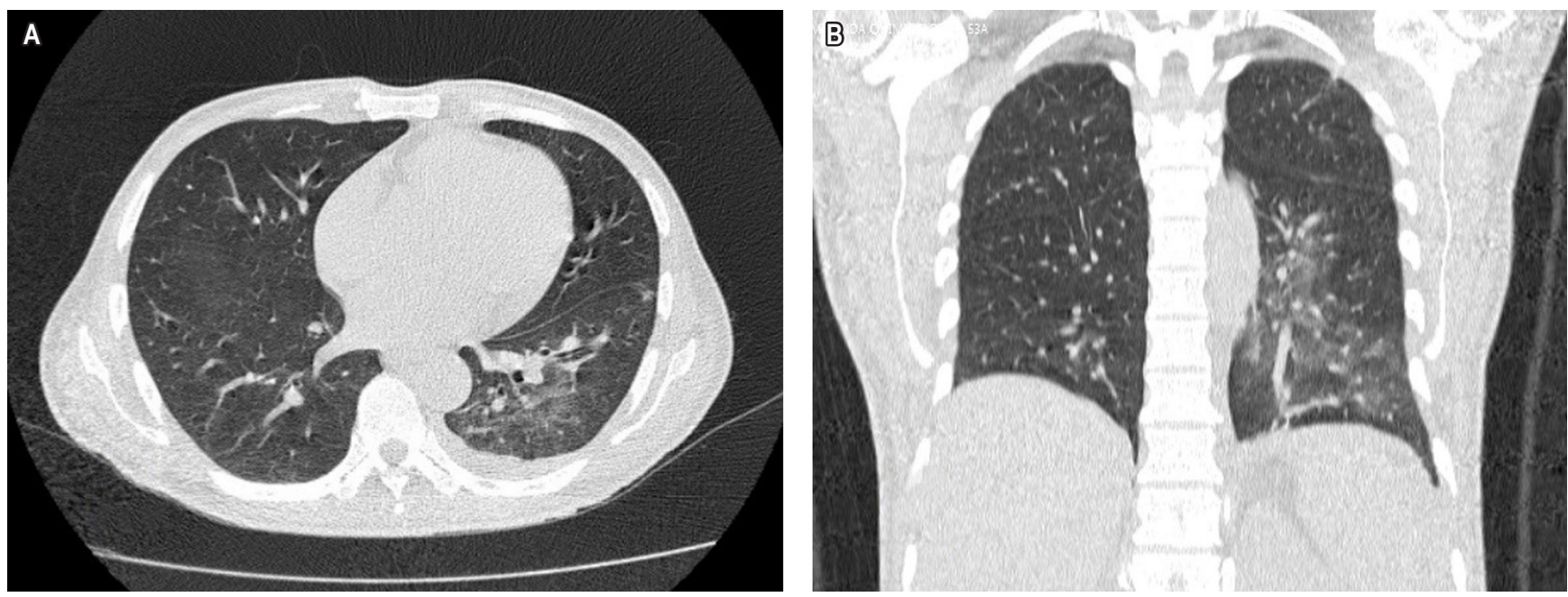

Figura 2. TAC de tórax. A. Corte transversal en el que se observa consolidación alveolar, con infiltración en ambas bases pulmonares en vidrio deslustrado. B. Corte coronal en el que se observa consolidación alveolar, con infiltración en base pulmonar izquierda en vidrio deslustrado. 

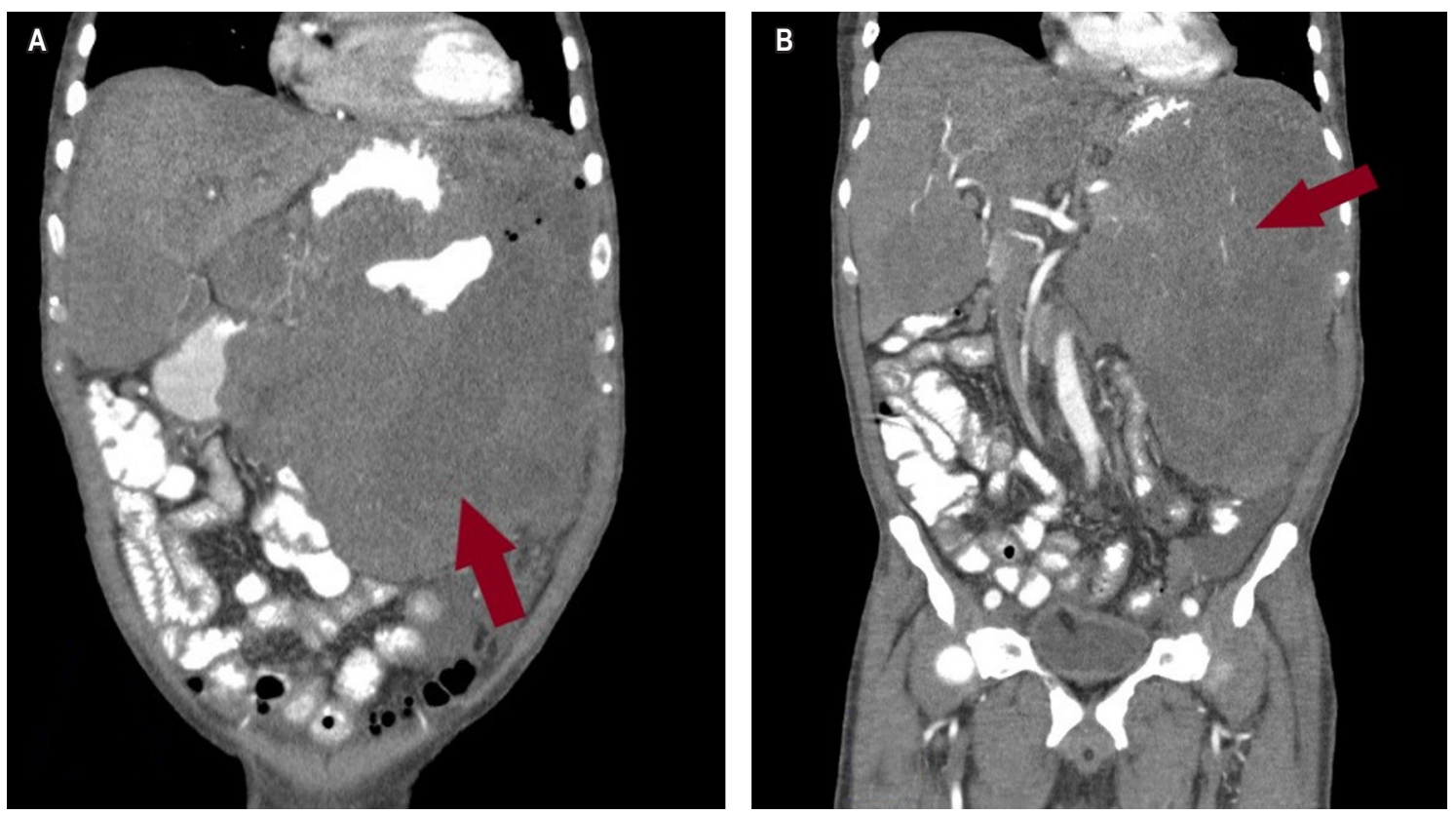

Figura 3. TAC de abdomen. A y B. En el corte coronal se observa una enorme masa tumoral de aspecto infiltrativo de aparente origen gástrico de aproximadamente $25 \times 25 \times 17 \mathrm{~cm}$, causado una extensa destrucción de la pared y de mucosa, infiltración endoluminal con crecimiento extragástrico e infiltración del bazo, del páncreas, de la raíz mesentérica, del omento mayor, del colon transverso y de asas intestinales delgadas; e infiltra el hilio hepático, como se observa en la flecha roja.
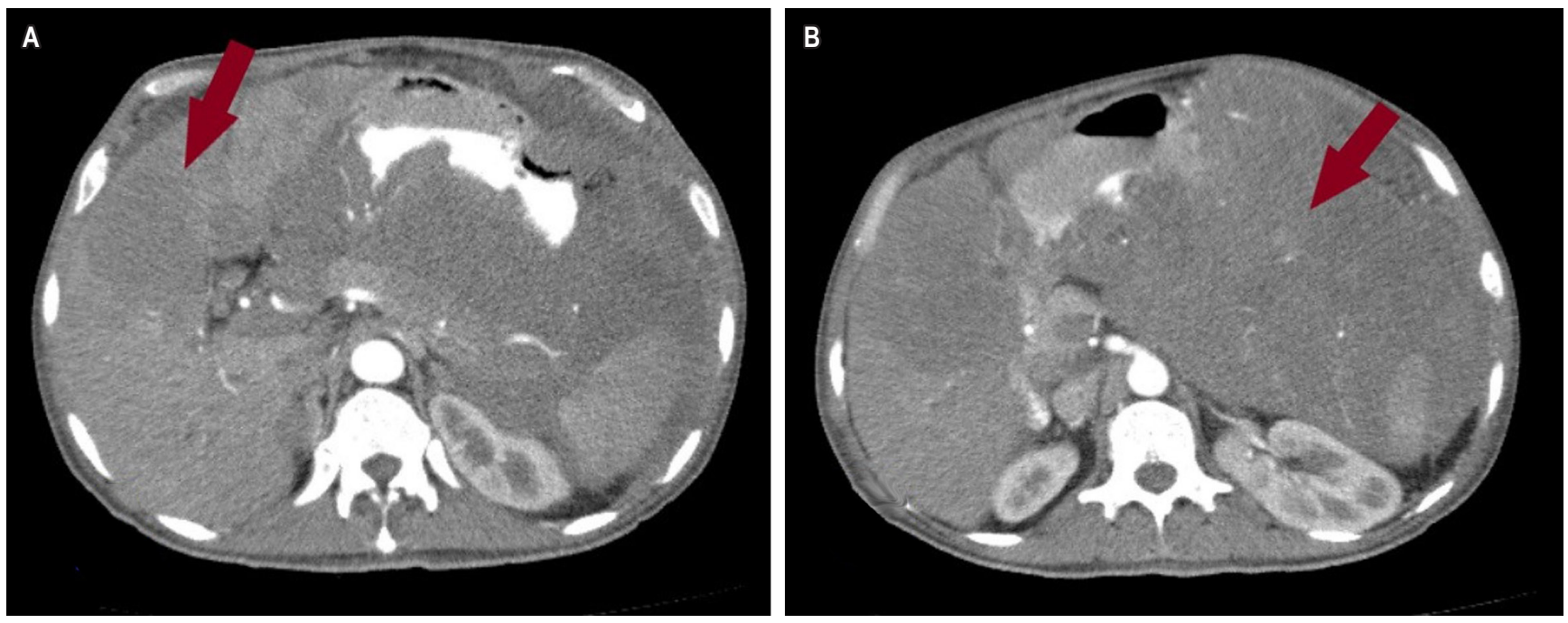

Figura 4. TAC de abdomen. A. Se observa a nivel hepático una lesión hipoatenuante de aspecto metastásico que mide $72 \times 41$ mm respectivamente en los segmentos hepáticos V y IV. B. En el corte coronal se observa una masa tumoral de aspecto infiltrativo de aparente origen gástrico, con crecimiento extragástrico con infiltración del bazo, páncreas, la raíz mesentérica, omento mayor, colon transverso, asas intestinales delgadas y el hilio hepático, como se observa en la flecha roja.

tumor estromal en 1837 y actualmente se propone que los GIST se originan de las células intersticiales de Ramón y Cajal $^{(7)}$. El GIST morfológicamente puede clasificarse de tipo fusiforme $(70 \%)$, epitelioide $(20 \%)$ y mixto (10\%); y puede mostrar estirpe muscular o neural. A diferencia del resto de los tumores del mesénquima, los GIST expresan el antígeno CD117 (parte del receptor C-kit), que puede demostrarse por inmunohistoquímica.

Los GIST son lesiones submucosas que parecen surgir de la muscular propia de la pared intestinal, los de origen intra- 
mural a menudo se proyectan extraluminal exofítico o intraluminal endofítico, y puede tener ulceración de la mucosa suprayacente; su tamaño puede ser extremadamente variable, desde pequeños casos incidentales hasta grandes masas, lo que casi siempre supera su suministro vascular y esto conlleva a extensas áreas de necrosis y hemorragia ${ }^{(8,9)}$.

El cuadro clínico es variable, depende del tamaño del tumor y la localización. Los síntomas más frecuentes son anemia, pérdida de peso, hemorragia gastrointestinal, dolor abdominal, disfagias y síntomas relacionados con el efecto de masa; pueden presentar clínica de abdomen agudo, obstrucción, perforación, ruptura y peritonitis ${ }^{(2)}$. En cuanto al diagnóstico, por lo menos entre el $10 \%$ y $30 \%$ se realiza de forma incidental, mientras que el $70 \%$ de los pacientes presenta una amplia gama de manifestaciones clínicas ${ }^{(10)}$.

La TAC y la resonancia magnética $(\mathrm{RM})$ son los estudios de imágenes de primera elección para los GIST. La TAC con contraste intravenoso permite identificar posibles hemorragias, calcificación intratumoral, estadificación preoperatoria y evaluación de la enfermedad metastásica, como en las lesiones hepáticas hipervasculares; mientras que la RM sirve para visualizar los tumores en el área pélvica y estudiar la extensión mesentérica y peritoneal. Aunque estas opciones de imagenología sirven para establecer un diagnóstico de presunción, ninguna es muy específica ${ }^{(11,12)}$. La tomografía por emisión de positrones (PET) generalmente no se usa para la evaluación de GIST, aunque puede ser útil en la detección temprana de la respuesta tumoral a la quimioterapia, así como para evaluar lesiones metastásicas equivocas $^{(12,13)}$.

El diagnóstico definitivo se obtiene mediante análisis histopatológico. La biopsia preoperatoria presenta riesgo de hemorragia debido a que los tumores son friables y generalmente se evita si se planea realizar cirugía definitiva. La aspiración con aguja fina (ACAF) puede proporcionar tejido adecuado para excluir otras neoplasias malignas $y$, cuando se combina con inmunohistoquímica y análisis de reacción en cadena de la polimerasa con transcriptasa inversa (RT-PCR) para mutaciones KIT, generalmente confirmará el diagnóstico ${ }^{(14)}$.

La inmunohistoquímica se utiliza para confirmar el diagnóstico, el marcador más utilizado es la CD117 en más del $95 \%$ de los casos, otros marcadores a menudo positivos son el CD34 (70 \%-90 \%), la actina del músculo liso (15\%$60 \%)$ y la desmina raras veces ${ }^{(13,15)}$. Aproximadamente, el $5 \%$ de los GIST no tiene expresión de KIT detectable.

Miettinen y colaboradores en un estudio analizaron 1765 casos de GIST gástrico con predominio del sexo masculino con edad media de 63 años. El tamaño del tumor varió de 0,5 a $44 \mathrm{~cm}$ con clínica de hemorragia gastrointestinal y su ubicación más frecuente fue el antro $(p<0,001)$. Se detectó expresión de KIT en el $91 \%$ de los casos, CD34 en el $82 \%$, actina del músculo liso en el $18 \%$ y desmina en el $5 \%(p<0,001)$. Las mutaciones se detectaron en el exón 11 de KIT en 119 casos y en el exón 18 en 86 casos en total $(p<0,001)^{(16)}$.

La cirugía es el estándar de oro para el tratamiento del GIST localizado y la terapia biológica con mesilato de imatinib se recomienda para casos con resección incompleta, tumores no resecables y cuando los tumores han progresado a enfermedad metastásica. En la resección quirúrgica completa, el porcentaje de recaída no es bajo, incluso después de la cirugía radical. Los tumores de riesgo bajo e intermedio generalmente tienen un buen resultado después de la cirugía, mientras que los tumores de alto riesgo generalmente reaparecen después de la resección y los resultados de la cirugía secundaria son generalmente pobres $^{(4,12,17)}$. Luigi Boni y colaboradores, en un estudio de resección quirúrgica de GIST con experiencia de 25 pacientes, demostraron que la resección completa se logró en el $88 \%$ de los casos, mientras que en el $12 \%$ no fue posible la resección radical en tumores de 1,2 a $30 \mathrm{~cm}$, lo que indica que la cirugía radical ofrece la posibilidad de supervivencia a largo plazo $^{(17)}$.

Los GIST se han convertido en un modelo de trabajo multidisciplinario en oncología: la participación de varias especialidades (gastroenterólogos, oncólogos, patólogos, cirujanos, biólogos moleculares, radiólogos y nutricionista) ha previsto avances en la comprensión de este tumor y la consolidación de una terapia dirigida: imatinib, como el primer tratamiento molecular efectivo en tumores sólidos ${ }^{(11)}$. El sunitinib inhibe el receptor del factor de crecimiento endotelial vascular (VEGFR), además del KIT y el receptor del factor de crecimiento derivado de plaquetas alfa (PDGFRA), y ha demostrado ser efectivo en pacientes intolerantes o refractarios al mesilato de imatinib en estudios más recientes ${ }^{(18)}$. La radiación ha sido limitada porque la dosis de radiación requerida para controlar el GIST probablemente excede la tolerancia de los tejidos circundantes ${ }^{(19)}$.

La supervivencia de los GIST avanzados generalmente enfrenta una morbilidad grave y una corta esperanza de vida, la mediana de supervivencia global para la enfermedad no resecable o metastásica fue de alrededor de 12 meses y de 9 a 12 meses para pacientes con recurrencia local; los casos con metástasis hepáticas y peritoneales no resecables de GIST han sido un problema difícil ya que los GIST malignos son refractarios a la terapia citotóxica convencional.

Luigi Boni y colaboradores, en un estudio entre 1987 y 2004 con 25 pacientes que fueron sometidos a resección quirúrgica por GIST, indicaron que el estómago fue el sitio más común, 
con resección completa en el $88 \%$ de los casos y en el 12\% no fue posible la resección radical. La supervivencia global a 5 años fue de $65 \%$ y $34 \%$ respectivamente, con una diferencia estadísticamente significativa entre tumores $<5 \mathrm{~cm}$ y $>10 \mathrm{~cm}$ de diámetro y entre resección completa e incompleta ${ }^{(17)}$.

\section{CONCLUSIONES}

Los GIST son tumores raros y los síntomas suelen ser inespecíficos. En la mayoría de casos el diagnóstico es fortuito, y la histología combinada con inmunohistoquímica y análisis de RT-PCR para mutaciones KIT es la que confirma el diagnóstico. Se presenta un caso de GIST gigante de localización extraintestinal e irresecable que se diagnosticó mediante biopsia percutánea y fue tratado con imatinib con una buena evolución hasta la actualidad.

\section{Conflictos de interés}

No existen conflictos de intereses.

\section{Fuente de financiación}

Propia de los autores.

\section{REFERENCIAS}

1. Frankel TL, Chang AE, Wong SL. Surgical options for localized and advanced gastrointestinal stromal tumors. J Surg Oncol. 2011;104(8):882-7. https://doi.org/10.1002/ jso. 21892

2. Sorour MA, Kassem MI, Ghazal Ael-H, El-Riwini MT, Abu Nasr A. Gastrointestinal stromal tumors (GIST) related emergencies. Int J Surg. 2014;12(4):269-80. https://doi. org/10.1016/j.ijsu.2014.02.004

3. Landi B, Bouché O, Guimbaud R, Aparicio T, Berger A, Bonvalot S, Buecher B, Blay JY, Boustière C, Coindre JM, Emile JF, Giovannini M, Lecomte T, Le Cesne A, Monges G, Napoléon B, Palazzo L, Chayvialle JA. Management of gastrointestinal stromal tumours of limited size: proposals from a French panel of physicians. Dig Liver Dis. 2011;43(12):935-9. https://doi.org/10.1016/j. dld.2011.04.008

4. Zhou L, Liu C, Bai JG, Wei JC, Qu K, Tian F, Tai MH, Wang RT, Meng FD. A rare giant gastrointestinal stromal tumor of the stomach traversing the upper abdomen: a case report and literature review. World J Surg Oncol. 2012;10:66. https://doi.org/10.1186/1477-7819-10-66

5. Gil González A, Hernández Pérez A, González Rodríguez D, Hernández Fernández DM, Castañeda Muñoz A. Tumor del Estroma Gastrointestinal (GIST). Presentación de un caso. Revista Médica Electrónica. 2009;31(1):1-3.

6. He YL. [Consensus and controversy of surgical diagnosis and treatment for gastrointestinal stromal tumor]. Zhonghua Wei Chang Wai Ke Za Zhi. 2013;16(3):201-3.

7. Mazur MT, Clark HB. Gastric stromal tumors. Reappraisal of histogenesis. Am J Surg Pathol. 1983;7(6):507-19. https://doi.org/10.1097/00000478-198309000-00001

8. Lin SC, Huang MJ, Zeng CY, Wang TI, Liu ZL, Shiay RK. Clinical manifestations and prognostic factors in patients with gastrointestinal stromal tumors. World J Gastroenterol. 2003;9(12):2809-12. https://doi. org/10.3748/wjg.v9.i12.2809

9. Tapia E, Roa JC. Tumores del estroma gastrointestinal (GIST): características clinico-morfológicas y perfil inmunohistoquimico. Int J Morphol. 2011;29(1):244-51. https://doi.org/10.4067/S0717-95022011000100041

10. Patil S, Jain S, Kaza RC, Chamberlain RS. Giant gastrointestinal stromal tumor presenting as a palpable abdominal mass: an unusual presentation. ISRN Surg. 2011;2011:894829. https://doi. org/10.5402/2011/894829

11. Poveda A, García Del Muro X, López-Guerrero JA, Cubedo R, Martínez V, Romero I, Serrano C, Valverde C, Martín-Broto J; GEIS (Grupo Español de Investigación en Sarcomas/Spanish Group for Sarcoma Research). GEIS guidelines for gastrointestinal sarcomas (GIST). Cancer Treat Rev. 2017;55:107-119. https://doi.org/10.1016/j. ctrv.2016.11.011

12. Lee T. Gastrointestinal Stromal Tumor (GIST) Presenting as a Huge Pelvic Mass. Geburtshilfe Frauenheilkd. 2013;73(1):70-73. https://doi. org/10.1055/s-0032-1328039

13. Zea-Arévalo FD, Juáre E, FQ -Duarte NM, GuerreroAvendaño G. Tumor del estroma gastrointestinal: hallazgos tomográficos y correlaciones anatomopatológica e inmunohistoquímica. Anales de Radiología México. 2013;12(4):241-7.

14. Bhambare MR, Pandya JS, Waghmare SB, Shetty TS. Gastrointestinal stromal tumour presenting as palpable abdominal mass: A rare entity. World J Gastrointest Surg. 2015;7(6):98-101. https://doi.org/10.4240/wjgs.v7.i6.98

15. Medeiros F, Corless CL, Duensing A, Hornick JL, Oliveira AM, Heinrich MC, Fletcher JA, Fletcher CD. KIT-negative gastrointestinal stromal tumors: proof of concept and therapeutic implications. Am J Surg Pathol. 2004;28(7):88994. https://doi.org/10.1097/00000478-200407000-00007

16. Miettinen M, Sobin LH, Lasota J. Gastrointestinal stromal tumors of the stomach: a clinicopathologic, immunohistochemical, and molecular genetic study of 1765 cases with long-term follow-up. Am J Surg Pathol. 2005;29(1):52-68. https://doi.org/10.1097/01.pas.0000146010.92933.de

17. Boni L, Benevento A, Dionigi G, Rovera F, Dionigi R. Surgical resection for gastrointestinal stromal tumors 
(GIST): experience on 25 patients. World J Surg Oncol. 2005;3:78. https://doi.org/10.1186/1477-7819-3-78

18. Antonescu C. Gastrointestinal stromal tumors. Curr Top Microbiol Immunol. 2012;355:41-57. https://doi. org/10.1007/82_2011_161
19. Demetri GD. Identification and treatment of chemoresistant inoperable or metastatic GIST: experience with the selective tyrosine kinase inhibitor imatinib mesylate (STI571). Eur J Cancer. 2002;38 Suppl 5:S52-9. https:/ / doi.org/10.1016/s0959-8049(02)80603-7 